\title{
A Perspective on Post-Pandemic Biomass Supply Chains: Opportunities and Challenges for the New Norm
}

\author{
Viknesh Andiappan ${ }^{1}$ (1) $\cdot$ Bing Shen $\mathrm{How}^{2} \cdot$ Sue Lin Ngan ${ }^{3}$ \\ Received: 28 January 2021 / Accepted: 4 May 2021 / Published online: 15 July 2021 \\ (c) The Author(s), under exclusive licence to Springer Nature Singapore Pte Ltd. 2021
}

\begin{abstract}
Since the dawn of the COVID-19 pandemic, we have seen increasing disruption in several economic sectors, especially the energy sector. This has forced decision-makers in the energy sector to reconsider how should the sector operate. With stumbling crude oil prices, it is evident that there is a need for a radical change in the way energy resources are utilized. This is where renewable energy supply chains such as biomass supply chains can play an important role. Biomass supply chains have been identified as a potential answer to the current issues faced by the energy sector that is still heavily reliant on fossil fuel. As such, this paper aims to examine the current challenges faced by biomass supply chains. Alongside this, potential opportunities that may arise for biomass supply chains in a post-COVID-19 world are also discussed with a specific focus on how the resiliency of biomass supply chains in six areas (i.e., supply availability, digitalization and automation, collaboration within the supply chain, community-focused energy production, social challenges and opportunities, and policy) can be improved in the post-pandemic scenario.
\end{abstract}

\section{Introduction}

The COVID-19 pandemic has caused major disruption in various economic sectors. It has also pushed decisionmakers in every sector to rethink their business operations. Among these sectors, the energy sector particularly the oil and gas industry is feeling the full-blown effects of the pandemic. This is evident as the world witnessed crude oil reaching historic low (or negative) prices towards the initial half of 2020 (Parameswaran 2020). This is because of the huge decline in global oil demands and the corresponding increase in oil supply (Rapier 2020).

Viknesh Andiappan, Bing Shen How and Sue Lin Ngan contributed equally to this work.

Viknesh Andiappan

v.murugappan@hw.ac.uk

1 School of Engineering and Physical Sciences, Heriot-Watt University Malaysia, 62200 Putrajaya, Wilayah Persekutuan Putrajaya, Malaysia

2 Research Centre for Sustainable Technologies, Faculty of Engineering, Computing and Science, Swinburne University of Technology Sarawak Campus, Jalan Simpang Tiga, 93350 Kuching, Sarawak, Malaysia

3 UKM-Graduate School of Business, Universiti Kebangsaan Malaysia, UKM, 43600 Bangi, Selangor, Malaysia
The impact caused by the pandemic has taught us many lessons. One major lesson is that the global energy sector will need to combat infrastructure vulnerabilities and adopt new ways of operation once the pandemic is over. For the past decades, we have seen a huge reliance on fossil fuels as a primary source of energy. However, the recent unstable fossil fuel prices may convince key decision-makers to accelerate the shift to clean energy globally. Thus, it is essential to look away from propping up old, polluting energy industries and work towards reducing infrastructure vulnerability by investing in more renewable energy supply chains. In this respect, IEA Bioenergy, the biofuel wing of the International Energy Agency (IEA), has strongly advocated for biomass to alleviate energy concerns amid the COVID-19 pandemic (Casey 2020). They particularly highlighted the flexibility and long-term viability of biomass resources, which is essential for the recovery of the energy sector (Bioenergy Insight 2020).

As such, this paper is aimed at examining the potential opportunities that may arise for biomass supply chains in a post-COVID-19 world. In addition, this paper highlights the areas in which the resiliency of biomass supply chains can be improved in the post-pandemic scenario. 


\section{Opportunities and Challenges}

The opportunities and challenges for biomass supply chains can be divided into six areas. These six areas include supply availability, digitalization and automation, supply chain collaborations, community focused-energy production, social opportunities, and policy. These areas are discussed further in the following sub-sections.

\section{Supply Availability}

Many developing countries highly depend on their agricultural activities for economic stability. Most agricultural activities generate a large supply of biomass. The biomass generated is often from unused parts of crops and contains high amounts of untapped energy. Despite such potential, the fluctuations in biomass supply have impeded the development of biomass-based industries in the past. A major factor that causes fluctuations in biomass supply is the regional and seasonal availability, where some biomass can only be harvested in certain periods in certain regions (Lo et al. 2021). This poses a huge threat to the resilience of the biomass supply chain. The reduction of biomass availability will cause a negative impact on the project economics given to its higher requirement on biomass cost (e.g., imported from other regions) (Gumte and Mitra 2019). On the other hand, developing countries such as Malaysia (How et al. 2019), India (Kapoor et al. 2020), and Thailand (Moran and Nasuwan 2019) are still involved in the low-value utilization of biomass (e.g., open-field burning, exporting raw biomass). This is often viewed as an easy alternative to investing large sums of capital to develop the local biomass industry. Unfortunately, having large portions of biomass trapped in these low-value activities would only make biomass availability scarcer. This in turn would cause the unit price of biomass to fluctuate according to its availability (i.e., the higher unit cost during the low-availability period) and, hence, making the entire biomass supply chain less favorable or infeasible (Sampim et al. 2017). Furthermore, some studies have discovered the influence of climate change on the harvesting of various crops. For instance, climate change is found to have negatively affected oil palm cultivation (Paterson et al. 2013). Due to climate change (i.e., change in rainfalls, average temperature, humidity), the soil conditions would change and eventually affect crop distribution and production (Trif and Oprea 2015; Lo et al. 2021). As a result, biomass availability will be influenced and, therefore, cause the biomass supply chain to become more vulnerable. In fact, supply uncertainty is among the key factors that would impede the development of bioeconomy (de Assis et al. 2016). Without having a reliable supply chain that is able to face the inevitable market swings and climate change, the resulting bioeconomy will likely suffer from increased economic risk (US Department of Energy 2016).

To address the challenges described above, there are several strategies (or opportunities) that can be considered. In the upstream of the supply chain, agronomy research will play a vital role to mitigate the mentioned supply risk. Agronomy research focuses on discovering methods to breed climate-resilient crops. To date, there are more than 7 million plant germplasm accessions stored in the 1750 seedbanks globally (Fu 2017). Such data is invaluable for researchers to identify useful and suitable genotypes that can be incorporated into the breeding process for developing climate-resilient crops. The future crops are expected to be resilient towards drought stress and salinity stress (i.e., heat stress and biotic stress), thus mitigating the vulnerability of the biomass supply chain. Proper planning on shifting the conventional crops to successfully modified crops is imperative in the near future.

Aside from assuring crop and biomass yields in the upstream, several counter-measures can be conducted in the downstream processing sectors to reduce the supply burden. First, this can be done by improving the overall conversion efficiency. A higher conversion efficiency indicates that higher product yield can be achieved using the same amount of raw materials. Researchers should continue exploring methods to enhance such production efficiency. For instance, chemical addition, particularly nanoparticles addition or the introduction of various novel catalysts (e.g. metal-organic framework (MOF) catalysts, transition metal dichalcogenides (TMDC) catalysts, and single-atom catalysts (SACs)), can improve the product yield of biological and thermochemical conversion processes to convert biomass to value-added products. Before that, the process upscaling studies for the production of these nanoparticles and novel catalysts remain as the research gaps that, therefore, require attention (Chen et al. 2018; Sun et al. 2019; Zhang et al. 2020).

Secondly, industry players can mitigate the supply risk by emphasizing proper management and scheduling strategies. Generally, the excess biomass feedstock can be stored for the use in future, especially when the biomass availability is in deficit (Lim et al. 2019). This enables the continuous biomass supply for production. The operation mode of storage facilities (i.e., decentralized or centralized) affects the overall feasibility (Seo et al. 2020). Thus, optimization for such location-allocation problems has to be performed. Aside from storing the biomass, another option is to store the excess biomass in their product forms. For instance, energy storage systems (thermal storage or battery devices) can be adopted for biomass-to-power pathways. Alternatively, 
plant owners can consider storing the energy from biomass in the form of various energy carriers, such as hydrogen (Bartela 2020) and ammonia (Zhou et al. 2019), to minimize the energy loss throughout the storage. Detailed analyses of the performance of each energy carrier form (e.g., life cycle analysis, techno-economic analysis, risk analysis, perception study) should also be conducted.

Finally, diversification of biomass for each biomass conversion process is another potential way to address supply risk. For example, various biomass feedstock can be blended and used for conversion technologies as long as its overall characteristics fit under the determined element acceptance range (Lim and Lam 2016). A significant portion of literature had shown that the blending of biomass could provide better, if not, comparable conversion efficiency when compared to its single feedstock counterparts. This enables higher operational flexibility for plant owners to make strategic decisions in biomass selection and allocation (Lim et al. 2018, 2019). Furthermore, there will be no need for importing biomass of the same kind from the market when encountering biomass deficits. Instead, other cheaper but suitable biomass or a mixture of biomass (in terms of characteristics) can be used as substitutes during the low-availability period. Therefore, more focus can be placed on analyzing a broader range of biomass conversion technologies that are flexible in handling various feedstocks.

On the other hand, policymakers should take responsibility for building social awareness and refurnishing national and regional policies to promote the higher-value utilization of biomass. A more detailed explanation of the role of policymakers can be found in the "Policy-Green Stimulus Packages" section. Figure 1 summarizes the framework between each supply chain stakeholder in addressing supply risk.

\section{Digitalization and Automation}

Under the current global health crisis, human contact within the supply chain should be minimized to avoid further transmission risks. Labor-dependent sectors were heavily struck and have shown poor resilience towards the pandemic (Bravery and Tomar 2020). Therefore, stakeholders should take this chance to review and retrofit their current supply chain model to make them more resilient towards such disruptions (i.e., the supply chain is still well-functional even under low-labor commitment). This can be achieved via digitalization and automation initiatives (De et al. 2020; Javaid et al. 2020).

Crop plantations and farming are the upstream activities that are usually labor-intensive. For instance, the use of automated robots for crop planting activities (e.g., mowing, planting, trimming, weeding, spraying) can loosen the labor requirement (Birrell et al. 2019; Fue et al. 2020). Besides,

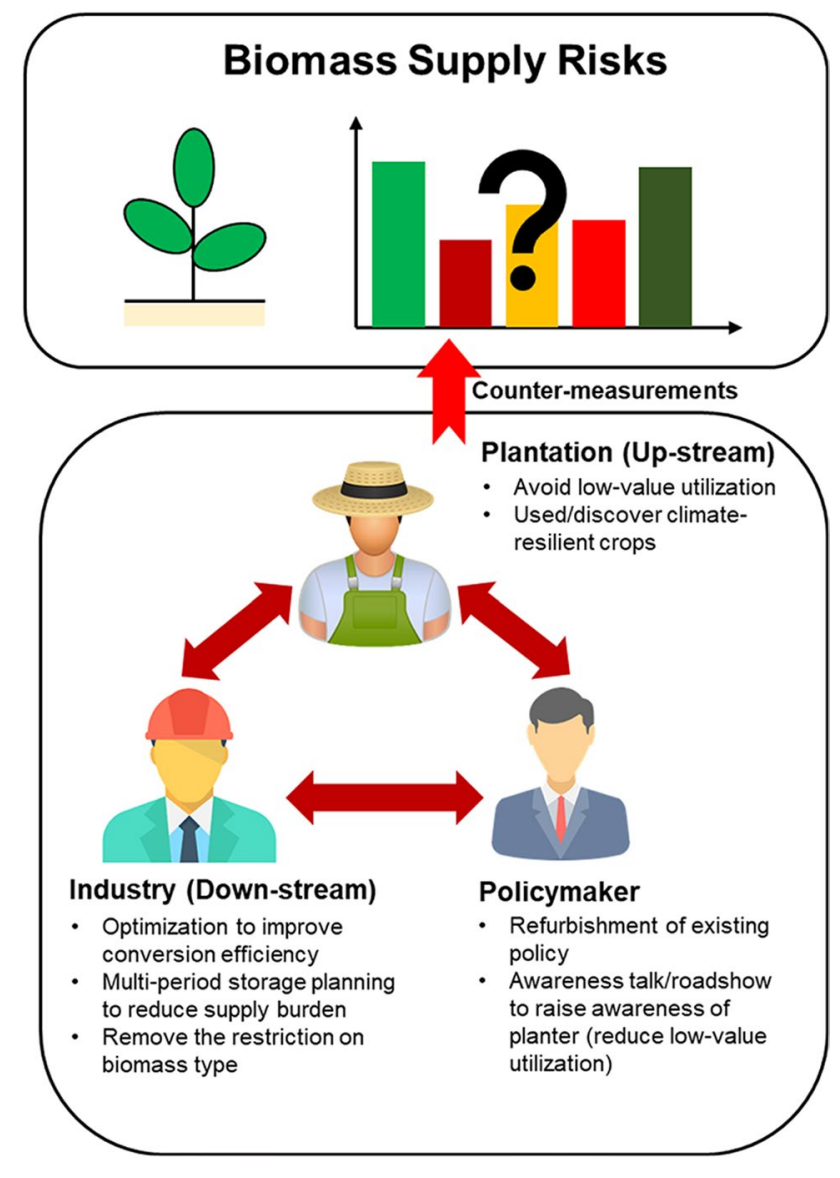

Fig. 1 A proposed framework to address supply issues in biomass supply chains

the internet of things (IoT)-enabled drones can also be used for information gathering by scouting from the air. Subsequently, the collected data can be served as the inputs that direct the next actions of the on-field agricultural robots (Burud et al. 2017). On the other hand, the collected data, including image data, can be useful for precision agriculture, where precise fertilization and other treatment can be performed based on the spatial and temporal variations in the plantation field (Cisternas et al. 2020). To enhance the robustness of the data analytics in agriculture sectors e.g., (precision agriculture, fruit ripeness detection) artificial intelligence (AI) tools can be considered (Wolfert et al. 2017).

Apart from that, process automation plays an important role in downstream activities to minimize the reliance on human involvement (e.g., automatic solids feeder with fuzzy controllers (Borges et al. 2020). On the other hand, the potential use of Big Data, cloud computing, and IoT in biomass conversion facilities had been extensively discussed in a few recent works (Belaud et al. 2019; Kabugo et al. 2020). For instance, IoT means that equipment sensors are remotely interconnected, therefore enabling remote data 
collection and analysis. In other words, the process operation and control of the biomass conversion facilities can now be monitored, accessed, and controlled remotely (Lim et al. 2021). This is attractive for efficient management, especially in a pandemic situation that encourages minimal human intervention. Aside from process monitoring and control, the collected data can also be used as a reference for storage management and scheduling (e.g., based on biomass or product storage time and material properties) (Jeong et al. 2019; Lim et al. 2021). Finally, other data-driven techniques can be useful for the synthesis of a resilient biomass supply chain. For example, digital twin technology (Teng et al. 2021) can be applied to develop a digital clone of the physical supply chain. The data obtained from the physical supply chain will be fed into the virtual model on a real-time basis, while the intelligence digital twin model can determine necessary corrective actions via supply chain optimization without the need for manual input. This can therefore contribute to resilient supply chain development.

\section{Collaboration Within Supply Chain}

The pandemic has evidently caused disruptions in supply chains, including biomass supply chains across the globe. Disruptions caused by the pandemic have pushed many factories and warehouses to shut down amid fears of safety and health impacts. As a result, biomass supply chains have seen drops in productivity. This, unfortunately, has created uncertainty on whether there is enough supply to keep the supply chains running in the long term (Dragov et al. 2020) to sustain the bioeconomy. This uncertainty would force most biomass users to obtain their biomass supply from various sources without tracing their origin or quality. This, in turn, could pose more challenges in predicting future supply trends and make planning more complicated. Thus, traceability and collaboration are two crucial attributes that biomass supply chains need to possess in the future to be more resilient (Dragov et al. 2020).

Blockchain technology can offer biomass supply chains the transparency they urgently need. Blockchain technology essentially is a virtual platform or storage space that connects all stakeholders in a supply chain and provides a transparent source of information about the supply chain (Saberi et al. 2019). It can operate without any third-party intervention. In past, blockchain technology has seen successful implementation in industries such as logistics, aviation, and food (Marr 2018; Mosinegutu 2019). For biomass supply chains, blockchain technology can provide information on the quality and origin of the biomass from suppliers. It will also provide real-time information on biomass supply availability. In addition to this, the information available via blockchain may allow stakeholders in the biomass supply chain to determine if their business is operating at an optimal level.

In theory, blockchain implementation requires that its stakeholders be open to collaboration and transparency. However, reality suggests that most stakeholders in biomass supply chains lack trust among each other. Biomass supply chains in general consist of stakeholders from independent small-medium enterprises that solely focus on the profit margins and competition with one another. Such focus, although practical, may pose a challenge for establishing collaboration in the industry, let alone transparency. Despite this, there are several methods that could help addressing the issue of competition. These may include game theory or agent-based models. Game theory models allow decisionmakers to capture the unique interests among stakeholders in the supply chain and allocate collective gains in based on their contributions to the supply chain (Andiappan et al. 2019). Meanwhile, agent-based models are used to model stakeholders in supply chains as a set of interacting agents in a defined environment. This allows their interactions to be simulated to understand the consequences or gains from their behavior in the supply chain (Singh et al. 2014). Having knowledge of the possible gains from collaboration may encourage stakeholders to take part in collaborations within the supply chain.

On the other hand, there is a low level of awareness about blockchain technology and its capability. This, in turn, has caused doubts over its implementation and prevented further investments. In the context of academia, there is a general lack of research work in the development of blockchain technology. Surveys on blockchain technology topics reveal a lack of high-quality journal publications that present or discuss the clear methodology behind it (Yli-huumo et al. 2016).

\section{Community-Focused Energy Production}

In times of crisis, energy security is an essential part of keeping economies afloat. The recent COVID-19 pandemic has forced decision-makers in the energy sector to revisit their energy generation portfolio. Energy generation in most parts of the world is still heavily reliant on fossil-powered centralized power generation systems. Centralized power generation systems may offer benefits in terms of efficient management. However, they do not possess the level of readiness to absorb disruptions during the crisis. In the context of COVID-19, certain power plants may need to be quarantined if any workers are deemed to have contracted the virus. Tight work restrictions such as reducing labor capacity only result in reduced productivity. Moreover, during power outages, the lack of technical support due to work restrictions may delay restoration efforts. This in turn creates an issue of energy shortage or insecurity (Massei 2020). 
There is a need to seek more robust solutions to energy security. However, there has been a possible solution to this for some time, and it comes in the form of decentralized energy generation. Decentralized energy generation refers to systems that generate and store power at or near where it will be consumed (Wu and Wang 2006). Doing this will make these systems more rapidly deployable, and they can offer effective response during a crisis as compared to centralized systems (Massei 2020). Furthermore, decentralized energy generation systems often depend on indigenous energy sources such as renewable feedstock. In this sense, biomass can be used as feedstock to generating power for local communities. Biomass can be obtained from sources such as food waste, municipal wastes, and agricultural waste (Kamm and Kamm 2004). Thus, biomass supply chains will need to play an important role in ensuring a stable supply of biomass feedstock.

However, the challenge related to decentralized energy generation systems is the economies of scale. Decentralized energy generation systems that are powered by biomass are often too costly to scale up (Babones 2020). This is because there is still a high number of subsidies focused on centralized systems powered by fossil fuel. Hence, more subsidies need to be made available for biomass energy generation systems to be more competitive in terms of cost (Egli 2020).

\section{Social Challenges and Opportunities}

One of the prominent challenges associated with a pandemic is the shortage of labor in biomass supply chains. The measure to contain and mitigate the spread of the virus such as movement restrictions has severely disrupted business as usual activities in biomass supply chains. This is due to the highly labor-intensive tasks associated with the biomass supply chain, particularly biomass harvesting and collection. For example, the second largest palm oil producer in the world, Malaysia, relies on $70 \%$ of foreign labor in the upstream activities including the harvesting and collection of oil palm biomass. This accounts for about $30-40 \%$ of the total production cost of palm oil (Chu 2020). Similarly, the sugarcane industry in Brazil and India, which served as the main source of energy matrix for biofuels, is also highly associated with manual works to cut, slash, and stack the cane prior to processing and production of sugar (Pashaei Kamali et al. 2018). Thus, the need to stay at home and the uncertainties arising from the pandemic (i.e., severity, duration) have triggered a lot of foreign workers to return to their respective countries of origin. This has created a huge threat to the biomass supply chain (International Labour Organization 2017). Despite this, the disruption in services and operations, in turn, provides an opportunity for employers to rethink the reliance of their business models on foreign workers and restructure the employee composition. It is undeniable that the working environment for biomass industry jobs is unfavorable to work with for the long term. For example, the working conditions of cane cutters are reported to be poor as it demands high physical effort (Leite et al. 2018). Labor workers in the palm oil biomass industry are also exposed to high occupational health risks such as musculoskeletal conditions, injuries, psychosocial disorders, and infectious diseases (Myzabella et al. 2019). These factors and issues allow industry players to turn the current crisis into an opportunity through reformulating and rebranding employment structures and working conditions within the industry. Authorities should also impose necessary measures to address the claims of poor social sustainability practices associated with the biomass supply chain, such as violation of human rights, child labor, poor health, and safety measure (Selfa et al. 2015).

Aside from this, the pandemic has caused severe economic loss to several businesses. This, unfortunately, has forced those employed to survive on stagnant or reduced wages. Despite this, there is an inherent unwillingness among the labor force to venture into biomass-related industries (The Straits Times 2020). This is mainly due to the social perception of jobs in the biomass sector, which often categorize as 3D (i.e., dirty, dangerous, difficult) jobs. According to Ashforth and Kreiner (2014), such social perception is mainly shaped by the cultural, historical, and demographic context. A 3D work, in general, refers to heavy and risky jobs, associated with manual, tiring, and dangerous activities that are characterized by monotony and very intense rhythm (Mucci et al. 2019). Nonetheless, it is important to recognize that 3D work is inevitable in society. Waste needs to be collected and managed properly for a cleaner environment. The "3D" components can serve as the best motivation for the technology advancement to design and develop solutions to ease the burden, reducing the risk of as said "3D" work. Thus, it is imperative for the local government, education agencies, as well as non-governmental institutions, to cultivate the right perception towards "3D" work and challenge the youth to find breakthroughs for such work. On top of that, it is also necessary to raise awareness on the importance and the benefits of biomass utilization to transition towards green growth for sustainable development. While most of the studies focus on the negative impacts of the biomass industry on the local environment, land uses, and social impacts, the benefits arising from the biomass supply chain and efforts to mitigate the claimed impacts should also be highlighted. For instance, the structured expansion of the oil palm plantation in Indonesia, Malaysia, and Brazil has increased the financial stability and the quality of life of the indigenous population significantly (Krajnc and Domac 2007; Azima et al. 2018). Furthermore, seminars and marketing campaigns can be held to educate and equip the public on the benefits, and the background 
information of the industry, subsequently, reduces their resistance to work in this industry. With the trend to transition towards industrial 4.0, education institutions can consider offering empowerment programs and courses that integrate the emerging professions (i.e., artificial intelligence, data analytics, supply chain management and optimization, risk management, and analysis) with sustainable development and green growth to prepare, nurture, and equip the youth to enhance the overall biomass supply chain.

\section{Policy_Green Stimulus Packages}

Based on the World Energy Balance report published by IEA in July 2020, fossil fuel remains the key source of energy, accounting for $81 \%$ of production in 2018 (International Energy Agency 2020a). However, movement and effort towards cleaner production and uptake of renewable energy are not new. In fact, this has been a common and global effort for the past few decades. The introduction of the international treaty-Kyoto Protocol—back in 1998 was a significant milestone in the effort to combat climate change and reduce global GHGs emissions. It emphasized the collaboration and resource transfer (i.e., knowledge, technology, investment) between developed nations and developing countries to combat the climate change issue together (United Nations and UNFCCC 1998). Unfortunately, the Kyoto Protocol did not achieve its target due to the lack of commitment from developing countries (Rosen 2015). One of the reasons that contributes to the ineffectiveness of such international treaties is the contradiction between policies at the national level. Take Malaysia as an example. In Malaysia, some policies have been introduced to grow the biomass industry. These include the National Green Technology Policy (2009) (KeTTHA 2011), National Renewable Energy Policy and Action Plan (2010) (Yatim et al. 2016), Sustainable Energy Development Authority Act (2011) (How et al. 2019), Biomass Strategy 2020 (2013) (AIM 2013), and Green Technology Master Plan (2017) (How et al. 2019). Meanwhile, Malaysia had practiced fuel policies for the past few decades which resulted in a high fiscal deficit and rising national debt ( $\mathrm{Li}$ et al. 2017). The fuel subsidy was finally reformed in 2014, and Malaysia then adopted the strategy to determine the domestic fuel retail prices based on the monthly average world crude oil price. Nonetheless, the on and off discussion on the potential revival of the fuel subsidy program in the country continues to convey mixed signals for the industry and society. A similar situation is observed in Indonesia. Even though Indonesia served as the signatory of the Convention on Biological Diversity, a convention committed to phasing out environmentally harmful subsidies, including fossil fuels by 2020 , the national level policy on the extensive fossil fuel subsidy (i.e., totaling up to 19.2 billion USD in the year 2019) (International Energy Agency 2020b) is still prioritized over the international treaties. This has resulted in Indonesia emitting the highest levels of emission intensity in the power sector among G20 members (i.e., $755 \mathrm{gCO} 2 /$ $\mathrm{kWh}$ ) (Suharsono and Gencsu 2019). Fossil fuel subsidies are among the common fiscal policies adopted by the authorities to ensure household well-being (i.e., access to energy) and encourage industrial growth. While fuel subsidies are intended to increase consumption among the rural and urban households and boost the production of specific sectors at the national level, it also served as a hindrance to the development of green energy and cleaner production. The lower oil prices resulting from international oil price fluctuation or through subsidy both serve as a motivator for the industry players to continue to use fossil fuel since renewable energy requires higher investment and levelized cost. Furthermore, lack of investment and access to finance also hinder the development of the biomass industry, even before the pandemic (Tang et al. 2012). Thus, the importance of the consistency and coherence of both national and international policy needs to be more palpable to boost biomass supply chains.

With the economic downturn caused by the pandemic, the issue is expected to further aggravate in the near future. Even though there is evidence indicating the promise in the biomass industry and a clear global intent on sustainable development, lack of green stimulus packages to revive the local financial needs while coordinating policy instruments for these efforts. Most of the introduced stimulus packages are highly focused on applying fiscal and/or monetary mechanisms to provide immediate financial relief measures for the people. There is no doubt that it is a crucial opponent in the stimulus packages. However, stimulus packages also can play an imperative role to kickstart pandemic-hit economies to either shape a low carbon future or further lock the world in the fossil fuel system, which is infeasible in a long run (Agrawala et al. 2020). Instead of merely providing financial support and aid to help corporations or personnel to stay in business via the conventional business model and fossil fuel systems, authorities should seek opportunities to re-strategize and transition them to more renewable sectors.

\section{Conclusion}

In conclusion, it is evident that biomass supply chains have an important role in solving energy security issues, especially during the pandemic. Despite such promise, this perspective paper has highlighted some crucial issues in which further effort is required before biomass supply chains can alleviate the world's heavy reliance on fossil fuel. It is worth noting that these issues may not necessarily stem from the pandemic. However, the pandemic has shed light on fallacies related to the world's fossil fuel reliance and the urgent need to solve issues within biomass supply chains so that they can play an important part in post-pandemic energy operations. 
Following this, several opportunities have been identified to aid the development of biomass supply chains.

Funding Authors acknowledge the support from (i) the School of Engineering and Physical Sciences (EPS) at Heriot-Watt University Malaysia, (ii) Swinburne University of Technology Sarawak Campus via Research Supervision Grant [2-5545 RSG], and (iii) MPOB-UKM Endowment Chair [Grant number: EP-2020-027].

Data Availability Data sharing is not applicable to this article as no datasets were generated or analyzed during the current study.

\section{Declarations}

Conflict of Interest The authors declare no competing interests.

\section{References}

Agensi Inovasi Malaysia, AIM (2013) National Biomass Strategy 2020: New wealth creation for Malaysia's palm oil industry. Agensi Inovasi Malaysia, Kuala Lumpur 1-32. https://doi.org/10.1016/j. ijggc.2012.07.010

Agrawala S, Dussaux D, Monti N (2020) What policies for greening the crisis response and economic recovery? https://doi.org/10.1787/ c50f186f-en

Andiappan V, Foo DCY, Tan RR (2019) Process-to-Policy (P2Pol): using carbon emission pinch analysis (CEPA) tools for policymaking in the energy sector. Clean Technol Environ Policy 21:1383-1388. https://doi.org/10.1007/s10098-019-01721-0

Ashforth BE, Kreiner GE (2014) Contextualizing dirty work: the neglected role of cultural, historical, and demographic context. J Manag Organ 20:423-440. https://doi.org/10.1017/jmo.2014.38

Azima AM, Choy EA, Lyndon N (2018) Oil palm smallholders in Sabah: the institution constraints of innovation. Int Inf Inst (tokyo) Inf 21:1677-1684

Babones S (2020) Poor economy of scale: renewable energy is about more than government policy. Natl Interes

Bartela $€$ (2020) A hybrid energy storage system using compressed air and hydrogen as the energy carrier. Energy 196

Belaud JP, Prioux N, Vialle C, Sablayrolles C (2019) Big data for agrifood 4.0: application to sustainability management for by-products supply chain. Comput Ind 111:41-50

Bioenergy Insight (2020) Renewable energy can support COVID-19 recovery. https://www.bioenergy-news.com/news/renewableenergy-can-support-covid-19-recovery-says-irena/. Accessed 29 Dec 2020

Birrell S, Hughes J, Cai JY, Lida F (2019) A field-tested robotic harvesting system for iceberg lettuce. J Field Robot 37:225245. https://doi.org/10.1002/rob.21888

Borges AS, Doraci I, Montano C et al (2020) Automatic solids feeder using fuzzy control: a tool for fed batch bioprocesses. J Process Control 93:28-42. https://doi.org/10.1016/j.jprocont.2020.07.006

Bravery K, Tomar A (2020) How companies and employees can make their best coronavirus comeback. World Economic Forum. In: World Econ. Forum. https://www.weforum.org/agenda/2020/ 04/coronavirus-covid-business-resilience-preparedness-skills/. Accessed 19 Aug 2020

Burud I, Lange G, Lilemo $M$ et al (2017) Exploring robots and UAVs as phenotyping tools in plant breeding. IFAC-PapersOnLine 50:11479-1484. https://doi.org/10.1016/j.ifacol.2017.08.1591
Casey JP (2020) IEA Bioenergy highlights potential for biomass amid Covid-19. In: PowerTechnology. https://www.power-techn ology.com/news/iea-bioenergy-highlights-potential-for-bioma ss-amid-covid-19/. Accessed 29 Dec 2020

Chen Y, Ji S, Chen C et al (2018) Single-atom catalysts : synthetic strategies and electrochemical applications. Joule 2:1242-1264. https://doi.org/10.1016/j.joule.2018.06.019

Chu MM (2020) Malaysian palm oil producers up perks to retain foreign workers. Star online

Cisternas I, Velásquez I, Caro A, Rodríguez A (2020) Systematic literature review of implementations of precision agriculture. Comput Electron Agric 176:105626. https://doi.org/10.1016/j.compag.2020.105626

De R, Pandey N, Pal A (2020) Impact of digital surge during Covid-19 pandemic : a viewpoint on research and practice. Int J Inf Manage 55:102171. https://doi.org/10.1016/j.ijinfomgt.2020.102171

de Assis CA, Gonzalez R, Kelley S et al (2016) Risk management consideration in the bioeconomy. Biofuels, Bioprod Biorefining 11:549-566. https://doi.org/10.1002/bbb.1765

Dragov R, Croce CL, Hefny M (2020) How Blockchain can help in the COVID-19 crisis and recovery. In: Int Data Corp. https://blogidcuk.com/blockchain-help-in-the-covid-19-and-recovery/

Egli F (2020) Renewable energy investment risk: an investigation of changes over time and the underlying drivers. Energy Policy 140:111428. https://doi.org/10.1016/j.enpol.2020.111428

Fu Y-B (2017) The vulnerability of plant genetic resources conserved ex situ. Crop Sci 55:2314-2328. https://doi.org/10.2135/crops ci2017.01.0014

Fue KG, Porter WM, Barnes EM, Rains GC (2020) An extensive review of mobile agricultural robotics for field operations : focus on cotton harvesting. AgriEngineering 2:150-174. https://doi.org/ 10.3390/agriengineering2010010

Gumte KM, Mitra K (2019) Bio-supply chain network design to tackle ethanol de fi ciency in India : a mathematical framework. J Clean Prod 234:208-224. https://doi.org/10.1016/j.jclepro.2019.06.160

How BS, Ngan SL, Hong BH et al (2019) An outlook of Malaysian biomass industry commercialisation: perspectives and challenges. Renew Sustain Energy Rev 113:109277. https://doi.org/10.1016/j. rser.2019.109277

International Energy Agency (2020a) World energy balances: overview

International Energy Agency (IEA) (2020b) Value of fossil-fuel subsidies by fuel in the top 25 countries, 2019

International Labour Organization (2017) Child labour in the primary production of sugarcane. Geneva

Javaid M, Haleem A, Vaishya R et al (2020) Industry 4. 0 technologies and their applications in fi ghting COVID-19 pandemic. Diabetes Metab Syndr Clin Res Rev 14:419-422. https://doi.org/10.1016/j. dsx.2020.04.032

Jeong B, Shin D, Im J et al (2019) Implementation of optimal two-stage scheduling of energy storage system based on big-data-driven forecasting — an actual case study in a. Energies 12:1124. https:// doi.org/10.3390/en12061124

Kabugo JC, Jämsä-Jounela SL, Schiemann R, Binder C (2020) Industry 4.0 based process data analytics platform: a waste-to-energy plant case study. Int J Electr Power Energy Syst 115:105508. https://doi. org/10.1016/j.ijepes.2019.105508

Kamm B, Kamm M (2004) Principles of biorefineries. Appl Microbiol Biotechnol 64:137-145. https://doi.org/10.1007/ s00253-003-1537-7

Kapoor R, Ghosh P, Kumar M et al (2020) Bioresource technology valorization of agricultural waste for biogas based circular economy in India : a research outlook. Bioresour Technol 304:123036. https://doi.org/10.1016/j.biortech.2020.123036

Kementerian Tenaga Teknologi Hijau dan Air (KeTTHA) (2011) The National Green Technology Policy. In: KeTTHA. http://portal. ppj.gov.my/c/document_library/get_file?p_1_id=17335\&folde rId=27605\&name=DLFE-4709.pdf. Accessed 22 Mar 2019 
Krajnc N, Domac J (2007) How to model different socio-economic and environmental aspects of biomass utilisation: case study in selected regions in Slovenia and Croatia. Energy Policy 35:6010 6020. https://doi.org/10.1016/j.enpol.2007.08.006

Leite MR, Zanetta DMT, Trevisan IB, et al (2018) Sugarcane cutting work, risks, and health effects: a literature review. Rev Saude Publica 52:80. https://doi.org/10.11606/S1518-8787.2018052000138

Li Y, Shi X, Su B (2017) Economic, social and environmental impacts of fuel subsidies: a revisit of Malaysia. Energy Policy 110:51-61. https://doi.org/10.1016/J.ENPOL.2017.08.015

Lim CH, Lam HL (2016) Biomass supply chain optimisation via novel Biomass Element Life Cycle Analysis ( BELCA ). Appl Energy 161:733-745. https://doi.org/10.1016/j.apenergy.2015.07.030

Lim CH, How BS, Ng WPQ, et al (2018) Debottlenecking biomass supply chain resources deficiency via element targeting approach. 70:2155-2160.https://doi.org/10.3303/CET1870360

Lim CH, How BS, Ng WPQ, Lam HL (2019) Debottlenecking of biomass element de fi ciency in a multiperiod supply chain system via element targeting approach. J Clean Prod 230:751-766. https:// doi.org/10.1016/j.jclepro.2019.05.127

Lim CH, Lim S, How BS, et al (2021) A review of industry 4. 0 revolution potential in a sustainable and renewable palm oil industry : HAZOP approach. Renew Sustain Energy Rev 135:110223. https://doi.org/10.1016/j.rser.2020.110223

Lo SLY, How BS, Leong WD et al (2021) Techno-economic analysis for biomass supply chain : a state-of-the-art review. Renew Sustain Energy Rev 135:110164. https://doi.org/10.1016/j.rser.2020.110164

Marr B (2018) 30+ Real examples of Blockchain technology in practice. In: Forbes. https://www.forbes.com/sites/bernardmarr/2018/ 05/14/30-real-examples-of-blockchain-technology-in-practice/? $\mathrm{sh}=35847 \mathrm{~b} 75740 \mathrm{~d}$. Accessed $29 \mathrm{Dec} 2020$

Massei CV (2020) COVID-19 will accelerate the revolution in energy systems. In: World Econ. Forum. https://www.weforum.org/agenda/2020/ 05/covid-19-accelerate-energy-revolution/. Accessed 19 Sep 2020

Moran J, Nasuwan C (2019) The haze problem in Northern Thailand and policies to combat it: a review. Environ Sci Policy 97:115. https://doi.org/10.1016/j.envsci.2019.03.016

Mosinegutu V (2019) Blockchain use cases apart from cryptocurrency in 10 successful companies. In: Coinzilla Acad. https://academy. coinzilla.com/blockchain-use-cases/. Accessed 29 Dec 2020

Mucci N, Traversini V, Giorgi G, et al (2019) Migrant workers and physical health: an umbrella review. Sustain 11(1):232. https:// doi.org/10.3390/su11010232

Myzabella N, Fritschi L, Merdith N et al (2019) Occupational health and safety in the palm oil industry: a systematic review. Int J Occup Environ Med 10:159-173. https://doi.org/10.15171/ijoem.2019.1576

Parameswaran P (2020) How will COVID-19 reshape Asia's energy future? In: Dipl. https://thediplomat.com/2020/05/how-will-covid19-reshape-asias-energy-future/. Accessed 29 Dec 2020

Pashaei Kamali F, Borges JAR, Osseweijer P, Posada JA (2018) Towards social sustainability: screening potential social and governance issues for biojet fuel supply chains in Brazil. Renew Sustain Energy Rev 92:50-61. https://doi.org/10.1016/j.rser.2018.04.078

Paterson RRM, Sariah M, Lima N (2013) How will climate change affect oil palm fungal diseases? Crop Prot 46:113-120. https:// doi.org/10.1016/j.cropro.2012.12.023

Rapier R (2020) Short term energy outlook shows impact of COVID-19 on energy sector. In: Forbes. https://www.forbes.com/sites/rrapi er/2020/05/17/short-term-energy-outlook-shows-impact-of-covid19-on-energy-sector/?sh=19fcd10d45ed. Accessed 29 Dec 2020

Rosen AM (2015) The wrong solution at the right time: the failure of the kyoto protocol on climate change. Polit Policy 43:30-58. https://doi.org/10.1111/polp.12105

Saberi S, Kouhizadeh M, Sarkis J, Shen L (2019) Blockchain technology and its relationships to sustainable supply chain management.
Int J Prod Res 57:2117-2135. https://doi.org/10.1080/00207543. 2018.1533261

Sampim T, Kokkaew N, Parnphumeesup P (2017) Risk management in biomass using fuel switching. Energy Procedia 138:10991104. https://doi.org/10.1016/j.egypro.2017.10.126

Selfa T, Bain C, Moreno R et al (2015) Interrogating social sustainability in the biofuels sector in Latin America: tensions between global standards and local experiences in Mexico, Brazil, and Colombia. Environ Manage 56:1315-1329. https://doi.org/10. 1007/s00267-015-0535-8

Seo SK, Yun DY, Lee CJ (2020) Design and optimization of a hydrogen supply chain using a centralized storage model. Appl Energy 262:114452.https://doi.org/10.1016/j.apenergy.2019.114452

Singh A, Chu Y, You F (2014) Biorefinery supply chain network design under competitive feedstock markets: an agent-based simulation and optimization approach. Ind Eng Chem Res 53:1511115126. https://doi.org/10.1021/ie5020519

Suharsono A, Gencsu I (2019) G20 coal subsidies: Indonesia. England $\&$ Wales

Sun Y, Wang Y, Yang G, Sun Z (2019) Optimization of biohydrogen production using acid pretreated corn stover hydrolysate followed by nickel nanoparticle addition. Int J Energy Res 44:1834 1857. https://doi.org/10.1002/er.5030

Tang A, Chiara N, Taylor JE (2012) Financing renewable energy infrastructure: formulation, pricing and impact of a carbon revenue bond. Energy Policy 45:691-703. https://doi.org/10.1016/j.enpol. 2012.03.022

Teng SY, Tous M, Leong WD, et al (2021) Recent advances on industrial data-driven energy savings : digital twins and infrastructures tonnes of oil equivalent. Renew Sustain Energy Rev 135. https:// doi.org/10.1016/j.rser.2020.110208

The Straits Times (2020) Malaysia's palm oil industry trying to hire local workers. SPH Digit. News

Trif A, Oprea AO (2015) The impact of climate changes on winter wheat crops and corn from Oltenia, between 2001-2014, compared with the reference period of 1981-2010. Agric Agric Sci Procedia 6:525-532. https://doi.org/10.1016/j.aaspro.2015.08.079

United Nation, UNFCCC (1998) Kyoto protocol to the United Nations framework convention on climate change. In: United Nations Framew Conv Clim Chang

US Department of Energy (2016) Strategic plan for a thriving and sustainable bioeconomy. https://www.energy.gov/sites/prod/files/2017/09/ f36/beto_strategic_plan_december_2016.pdf . Accessed 29 Apr 2021

Wolfert S, Ge L, Verdouw C, Bogaardt M (2017) Big data in smart farming - a review. Agric Syst 153:69-80. https://doi.org/10. 1016/j.agsy.2017.01.023

Wu DW, Wang RZÃ (2006) Combined cooling, heating and power : a review. 32:459-495. https://doi.org/10.1016/j.pecs.2006.02.001

Yatim P, Mamat MN, Mohamad-Zailani SH, Ramlee S (2016) Energy policy shifts towards sustainable energy future for Malaysia. Clean Technol Environ Policy 18:1685-1695. https://doi.org/10.1007/ s10098-016-1151-x

Yli-huumo J, Ko D, Choi S et al (2016) Where is current research on Blockchain technology? - a systematic review. PLoS ONE 11:1-27. https://doi.org/10.1371/journal.pone.0163477

Zhang X, Teng SY, Chun A et al (2020) Transition metal dichalcogenides for the application of pollution reduction: a review. Nanomaterials 10(6):1012. https://doi.org/10.3390/nano10061012

Zhou M, Wang Y, Chu Y et al (2019) Ammonia as an environmentally benign energy carrier for the fast growth of China. Energy Procedia 158:4986-4991. https://doi.org/10.1016/j.egypro.2019.01.668

Publisher's Note Springer Nature remains neutral with regard to jurisdictional claims in published maps and institutional affiliations. 